\title{
Communicating mathematics through images: A multimodal study of Year One students' meaning- making when working with mathematics textbooks
}

\author{
Maria Norberg \\ Mid Sweden University, Sweden
}

This article focuses on how Swedish Year One students (age 7-8) make meaning when working with images in mathematics textbooks. Images include textbook images, but also students' self-drawn images used as support for calculation. The focus was (1) what the images in the exercises were designed to offer (the designed affordance), and (2) what the students discovered when working with them. The data material consisted of video transcripts of 18 students working with subtraction exercises from mathematics textbooks. The results showed that the students sometimes discovered the designed affordance and sometimes did not. The students who discovered the designed affordance sometimes used the image when performing the calculations, while others did not. Some students expressed that images in mathematics textbooks are for those who find mathematics difficult, and that completing exercises without using the images was desired. The students' approaches to images were discussed in two specific cases: First, the students' desire to use mathematical symbols rather than images may lead to students not discovering the mathematics content that the exercise is designed to offer. Second, the use of mathematical symbols rather than images may lead to students not discovering themselves as mathematical individuals.

\section{ARTICLE DETAILS}

LUMAT General Issue Vol 9 No 1 (2021), 945-970

Received 13 January 2021 Accepted 15 November 2021 Published 3 December 2021

Pages: 26

References: 52

Correspondence: malin.norberg@miun.se

https://doi.org/10.31129/ LUMAT.9.1.1480

Keywords: Affordance; design; images; mathematics textbooks; meaning-making

\section{Introduction}

We make meaning using many different images every day, including images found on our smartphones, in newspapers and books, on television, flyers, and traffic signs, to mention a few sources. So, images play an essential role in communication (Kress \& van Leeuwen, 2006). Making meaning when encountering images is thereby of great importance. This article focuses on images of a specific kind: images in mathematics textbooks.

The visual has always played a role in school (Jewitt, 2014). Images symbolise the concrete world, while mathematical symbols (numbers and other symbols expressing mathematics operations, e.g., equals sign) represent the abstract (O'Halloran, 2005). Mathematics highly relies on visual information (e.g., Arcavi, 2003; Presmeg, 2006), and visualisation is central in mathematics education (Arcavi, 2003). However, research on visual learning in mathematics education is comparatively new (Presmeg, 
2020). Cooper and Alibali (2012) suggested more research about how students interpret different kinds of visual representations.

An image is always coded and needs to be interpreted; it is perceived as transparent if the individual already knows its code (Kress \& van Leeuwen, 2006). This is often implicit knowledge; people can rarely put images into words directly and explain how we interpret an image (Kress \& van Leeuwen, 2006). This underpins the importance and complexity of studying images in educational settings. Kress (2010) formulated this by stating, "Images are (as yet, relatively) difficult to describe and analyse since, unlike writing, they are rarely composed of clearly discrete constituent entities, as words are" (47). Images are also used in different ways within a given textbook (Norberg, 2021). Thus, mathematics textbook images can be considered challenging to perceive, and since working with primary school mathematics textbooks generally involves working with images, this is crucial.

Furthermore, mathematics teaching largely involves working with mathematics textbooks. It is well known that the teacher plays an important role in teaching (e.g., Pansell \& Andrews, 2017; Segerby \& Chronaki, 2018). But, regardless of how the teacher stages their teaching, mathematics teaching involves students' individual work with the textbook (Boesen et al., 2014; Österholm, Bergqvist, Liljekvist \& van Bommel, 2016). Therefore, it is important to study students' individual work with the textbook, which is the focus of this article.

Images in mathematics textbooks are often designed to offer specific content to guide the learner to a particular meaning-making (Norberg, 2019, 2021). This is because the mathematics textbook is a teaching resource aiming for specific learning, which means that the particular meaning being made while working with the textbook is important. This specific offer is theoretically understood as the designed affordance. The designed affordance points out the affordance the learner needs to discover in order to solve the exercise correctly. The concept of affordance derives from Gibson's (1986) work and emphasises the potential meaning and the relation between textbook image and learner. Hence, it is important to highlight the designed affordance and the meaning made when studying students' work with mathematics textbooks' images to determine whether students discover the designed affordance. Suppose the student does not discover the designed affordance. In that case, this is of great importance for textbook authors, illustrators, publishers, and teachers as it would imply that the students do not complete the exercise as intended. Here, it is important to state that 
textbooks include images not related to calculation, images with a more decorative aim; those images are not in focus in this article.

The study presented in this article stems from an overarching interest in students' meaning-making when working with mathematics textbooks. A previous study (Norberg, accepted for publication) stated the importance of the images in the mathematics exercises in students' meaning-making. This directed my interest to analyse further the specific meaning students made when working with the images they encountered in the exercises. The study derives from an approach that focuses on meaning-making and multimodality (Kress, 2010; Selander \& Kress, 2010). Multimodality recognises meaning in all resources for communication (modes), such as images, writing, and speech. It might be seen as a bit narrow in focus to select one of the modes included in the textbook, but this was made because the image mode appeared to be of particular interest. This can be understood as an in-depth study on one of the modes included in the multimodal text. This article will also discuss how working with mathematical textbooks' images might influence students' perceptions of themselves as mathematical or not.

This article's aim is to get a deeper understanding of students' meaning-making when working with mathematics textbooks, focusing on images connected to calculation in Swedish Year One textbooks. As the textbook is designed to offer specific content, the study will be related to that content, described as the designed affordance. Attention is directed to both the textbook's images and images drawn by students while working with the textbook. This is done with a delimitation to the mathematical content of subtraction. The following research questions are addressed:

- How do the students relate to images in their meaning-making?

- How do the students' meaning-making relate to the textbooks' designed affordances, focusing on images?

\section{Literature review}

Mathematics textbook images have been studied for a long time. In the research field, different concepts have been applied to images used for calculation in mathematics textbooks: pictures, illustrations, visual representations, and images. Sometimes, different categories of images are mentioned, such as iconic images and symbolic images. In this study, the concept of image is used because it aligns with the theoretical approach that understands image as one of the modes in a multimodal 
text. Images form a large part of the content of mathematics textbooks for younger students (Norberg, 2021). The exercises' mathematical content is often found in the image, while the image rarely answers a task (Norberg, 2021).

More than 40 years ago, researchers stated that students must learn how to read images (Levie \& Dickie, 1973) and develop strategies to guess what answers teachers wanted (Byrne \& Mason, 1976). Also, students need to perceive the eventual actions depicted in the images to use them (Campbell, 1978, 1979, 1981). Campbell found that students did not always find the mathematical content that was supposed to be seen in the images, and concluded that images could be supportive, but only when students understood them. Altogether, mathematics textbook images have been an object of study in mathematics education for a long time. These studies are still relevant in many respects, and the questions they ask remain valid.

Studies on students' work with images in mathematics textbooks have different focuses, including various image types (Presmeg, 1986), gender (Moser \& Hannover, 2014), visually impaired students (Sedaghatjou, 2018; Emerson \& Anderson, 2018), or eye-tracking connected to specific mathematical content (Jr-Hung Lin \& Lin, 2014; Roy, Inglis, \& Alcock, 2017). Several studies have used a multimodal approach (Freeman et al., 2016; Sedaghatjou, 2018; Teledahl, 2017; Wilson \& Landon-Hays, 2016), and two of these also a social semiotic approach (Teledahl, 2017; Wilson \& Landon-Hays, 2016), which is consistent with the study reported in this article. Wilson and Landon-Hays (2016) studied how six middle-school teachers used images to teach students aged 11-13 four subjects, of which mathematics was one. Their study used a case-study design and the following concepts from Kress and van Leeuwen's (2006) visual grammar to analyse the data: framing, vantage point, subject of image, orientation, background, and colour. The results showed that, in mathematics, humans were more seldom pictured than in the other subjects. Typical images were figures or shapes that the researchers described as generalised images, which were often black and white and most often on white backgrounds.

Students use mathematics textbooks in different ways (Teledahl, 2017) and the same affordances help some students and hinder others (Moyer-Packenham et al., 2016). Moyer-Packenham et al.'s (2016) conclusion derives from analysing 100 students age 3-8 using mathematical apps on touch-screen devices. Teledahl (2017) analysed students' (9-12 years old) writing when problem-solving. The results showed that the students used images, writing, mathematical symbols, and layout in different ways. Teledahl (2017) also found that images in mathematics textbooks 
sometimes contained contextual information with the problem to be solved (e.g., the farmer was illustrated even though she was not part of the calculation).

The use of images when working with mathematics and if they support the students is debated. Two recent Turkish studies showed that students are supported by images when solving problems (Ulu \& Akar, 2016; Usta, Yilmaz, Kartopu \& Kadan, 2020). Ulu and Akar (2016) studied 370 9-10-year-old students and found that the use of images meant that more students answered the problems, and that more students answered correctly. Usta, Yilmaz, Kartopu and Kadan (2020) studied 108 910-year-old students. An experimental group received image support and a control group were offered the problems without images. The results showed that the experimental group did better than the control group. This could be compared to Dewolf, van Dooren, Cimen and Verschaffel (2013), who found that images had no impact on students solving word problems. 635 total students, age 10-11, from Belgium and Turkey participated. The result showed that images did not have an effect on how the students solved word problems, and the authors discussed three possible reasons for this. First, the students may not have looked at the images. Second, the students may not have found support in the images. Or, third, the students may have found support in the images, but made no use of that support due to former experiences of solving word problems. In another study of visual representations in problem-solving, Cooper and Alibali (2012) compared 93 American higher education students' performance using diagrams and images. They saw that images helped some of the students, depending on the students' backgrounds.

Students use the images as support for solving tasks regardless of the design and the actual purpose of the illustrations. This was shown by Jellis (2008), where 128 students aged 7-8 years from three schools participated. The students had difficulty deciding whether the information in the illustration was relevant or irrelevant to solving the task. This meant that the information in the illustrations sometimes misled the students.

Students have greater use of images they draw themselves than those offered in the problems, Ulu and Akar (2016) stated. Teledahl (2017) found that the majority of students drew images when problem-solving. Freeman, Higgins, and Horney (2016) saw that younger students drew images more often than older students, in a multimodal approach studying 42 students age 8-13 writing mathematical notes using digital technologies. Moreover, Teledahl (2017) categorised the self-drawn 
images as either iconic (e.g., hens or pigs) or symbolic (e.g., dots or lines). The images were often complemented with numbers and words, and sometimes a sequence was drawn. The result also showed that the problem-solving often started when the student began drawing the image; sometimes, the students manipulated the image by erasing or crossing out objects. Almost a third of all students used images as part of their answers, rarely without complementation from other resources such as writing and mathematical symbols. Students drawing images were also studied by Jones (2018). This study focused on higher education students' prototype images using 205 surveys and 23 interviews. The prototype images were useful but needed to be complemented with other images or nonvisual representations. Jones also problematised that a prototype image may give a generalised view of the mathematical content while a more complex image rather makes perception harder, as it contains a lot of information.

Similar to the present study, a study of more than 400 Japanese students, age 612, interpreted images showing different subtraction situations (Kinda, 2010). Subtraction as a mathematical operation (understood as "something is taken away") was easier for students to recognise than a mathematical operation recognised as two amounts being compared. The comparison situation tended to be interpreted as a form of the taking-away situation.

In sum, textbook images have long been an object of study. There are various types of research on the subject. Studies have shown that images are essential when working with textbooks but that they are complex to perceive and that the same image can be helpful for some learners but not others. There are also studies showing that images do not impact students' work. This article will contribute new knowledge on how students make meaning when working with images in mathematics textbooks. With a deeper understanding of students' meaning-making, young students' perspective on the use of images in mathematics textbooks could be broadened. Thus, mathematics education with a focus on images could be developed.

\section{Conceptual framework}

The study reported in this article is based on a multimodal design theoretical approach (Selander \& Kress, 2010), which refers to the social semiotic field (see, for example, Kress, 2010) where meaning-making is essential. Meaning-making is an activity in a social and cultural context in which an individual seeks to understand the world (e.g., Kress, 2010; Selander \& Kress, 2010). Meaning-making is always 
multimodal, implying that communication is made through various modes (e.g., speech, gesture, text, and image). Modes are understood as resources for communication and meaning-making (Kress, 2014). All modes offer potential for meaning-making (Jewitt, 2016; Kress \& van Leeuwen, 2001), and "different modes offer different potentials for meaning-making” (Kress, 2010, p. 79), with advantages as well as limitations (Jewitt, Bezemer, \& O’Halloran, 2016).

Mathematics has been claimed to be a multimodal subject (O'Halloran, 2005), a fundamental point of departure for this article. The subject has a long history of using various modes for communicating mathematical content. For instance, specific mathematical content can be communicated in different ways, such as using a bar chart, writing, or mathematical symbols in a diagram. As mentioned in the introduction, this article reports on a multimodal study in which particular focus is given to one mode, rather than a study in which only one of the modes is studied. This means that the analysis focused on how students made meaning when working with mathematics textbooks concerning the image mode. This study also, as mentioned earlier, analyses the part of teaching that involves students' individual work with the mathematics textbook. This does not mean that the teacher's important role is neglected, but that the student's individual work is given attention. The intention is not to provide a micro-level analysis but rather to study how students work with selected exercises in a mathematics textbook focusing on the images. To understand students' working with textbook images, the concepts of meaning-making, design, and affordance will be described in the following paragraphs.

Meaning-making is a creative activity in which the individual redesigns already existing representations (Selander, 2017; Selander \& Kress, 2010). In the present study, meaning-making occurs when the students work with the textbook images. The textbook images, when redesigned by the students' meaning-making, produce new representations. The students' meaning-making is always new and can never be a replica of the textbook author's meaning-making of the same content (Bezemer \& Kress, 2010). The present study focuses on students' meaning-making when working with textbook images and relates them to the images designed affordances. Designed affordance is defined as the affordance needed to solve the exercise so that the mathematical content focused in the exercise is discovered.

The design concept concerns how teaching resources are designed and how individuals are involved in designing their learning situations (Selander \& Kress, 2010). Design refers to both objects and conditions for communication and is 
understood as a communicative process in which the individual, through her involvement, depicts representations (Kempe \& Selander, 2008; Selander \& Kress, 2010). In this article, the concept of design refers to how the textbook is framed and the specific affordance, the designed affordance, that the student is intended to discover.

Affordance is considered a communication resource and the potential meaning that can be created (Gibson, 1986). In the present study, interest is directed to both the textbook's designed affordance and the affordance the students discover. Danielsson and Selander (2016) described affordance as offered meaning potential, or opportunities and limitations. There may be more given affordances for an individual's meaning-making when working with a resource, but different individuals can also discover different affordances (van Leeuwen, 2005). For example, a chair is likely to be found as something to sit on, but also as something to use to lock a door. According to Selander and Kress (2010), there will always be new potentials waiting to be discovered. Jewitt (2016) stated that affordance is a controversial and debated concept in multimodal research because it may have partly different meanings. For this article, I focus on the dualistic significance of the concept of affordance. On the one hand, interest is directed to the images designed affordances and, on the other hand, the students' meaning-making.

To achieve an in-depth understanding of students' meaning-making when working with mathematics textbook images, the results will be discussed in relation to how the textbook can help shape students' perceptions of themselves as mathematical individuals.

\section{Method}

This article seeks to understand how students make meaning when working with images in mathematics textbooks. A previous study (Norberg, accepted for publication) suggested that images were vital in the students' meaning-making. Images play a crucial part in students' meaning-making when they work with their textbooks. To study this, the images' designed affordances (the potential meaningmaking the student needed to discover to solve the exercise correctly) were analysed and the students' meaning-making. Various types of data were used: textbook exercises, video transcripts in which students work with the same exercises, and the students' own representations (i.e., their answers to the mathematics exercises). In this section, data collection and the framework for analysis will be described. 


\subsection{Collection of data}

18 individual video transcripts of Year One students (age 7-8) were collected to study their work with mathematics textbook images. The school was chosen from a convenience sample and is located in a medium-large city in Sweden. All of the students whose caregivers gave consent for inclusion in the study participated. Before data collection, I spent one week in the class, getting to know the students, so that the presence of a new adult would not feel uncomfortable for them. I have 12 years of experience as a compulsory-level teacher, which made interactions with the students quite natural. The aim was to study students in a situation that was as realistic as possible. Most natural would have been to study students in the classroom, during mathematics lessons. Since mathematics textbook work is often individual and silent, recordings of entire classes would provide little insight into the meaning-making of individual students. Therefore, I sat with one student at a time, in a room next to the classroom, in order to focus on the students' meaning-making in detail. This approach allowed me to watch the student working and ask the student follow-up questions.

The video material consists of 450 minutes of film, approximately 25 minutes per student, ranging from 19 to 44 minutes. The videos were recorded using a tablet. I chose a tablet because this was familiar to the students, who used tablets in their everyday learning. Therefore, the presence of a tablet did not draw any particular attention from the students; rather, it provided an undramatic way of documenting the students in their meaning-making. The tablet was placed obliquely above the student who sat at a table beside me. This allowed both the student, the textbook, and me to be seen in the image. The student started working on the exercise on her own. After some time, to understand how the student made meaning from the exercise, I asked questions of an investigative nature, such as "Can you tell me how you went along on this side?", "How did you know how to work with this exercise?", or "I saw that you did something with this image here, can you show me?" If the student had difficulty getting started with the exercise, I provided support in the form of questions such as "Can you use the images to solve the exercise?" or "Why do you think these dots are here?" (while pointing to the image in the task).

The textbook series used in the studied class is well known and used across Sweden. It consists of two levels: Favoritmatematik (Favourite Mathematics) $1 A$ and 1B (Ristola, Tapaninaho, \& Tirronen, 2012a, 2012b) and Mera favoritmatematik (More Favourite Mathematics) 1A (Haapaniemi, Mörsky, Tikkanen, Vehmas \& Voima, 2013). Mera favoritmatematik is considered a more challenging textbook series than 
Favoritmatematik. The exercises were chosen based on the results of a quantitative study (Norberg, 2021) using the following criteria: They should address subtraction as an arithmetic operation, and the exercises should be commonly used and show breadth according to how the different modes were used. Also, the mathematical content should not be new for the students; therefore, no exercise from Mera favoritmatematik $1 B$ was chosen. The exercises (Figures 2-8 in the results below) were colour-copied and handed out to the student, one at a time. The exercises are shown with the publisher's permission. For a definition of exercise and task, see Figure 1 below.

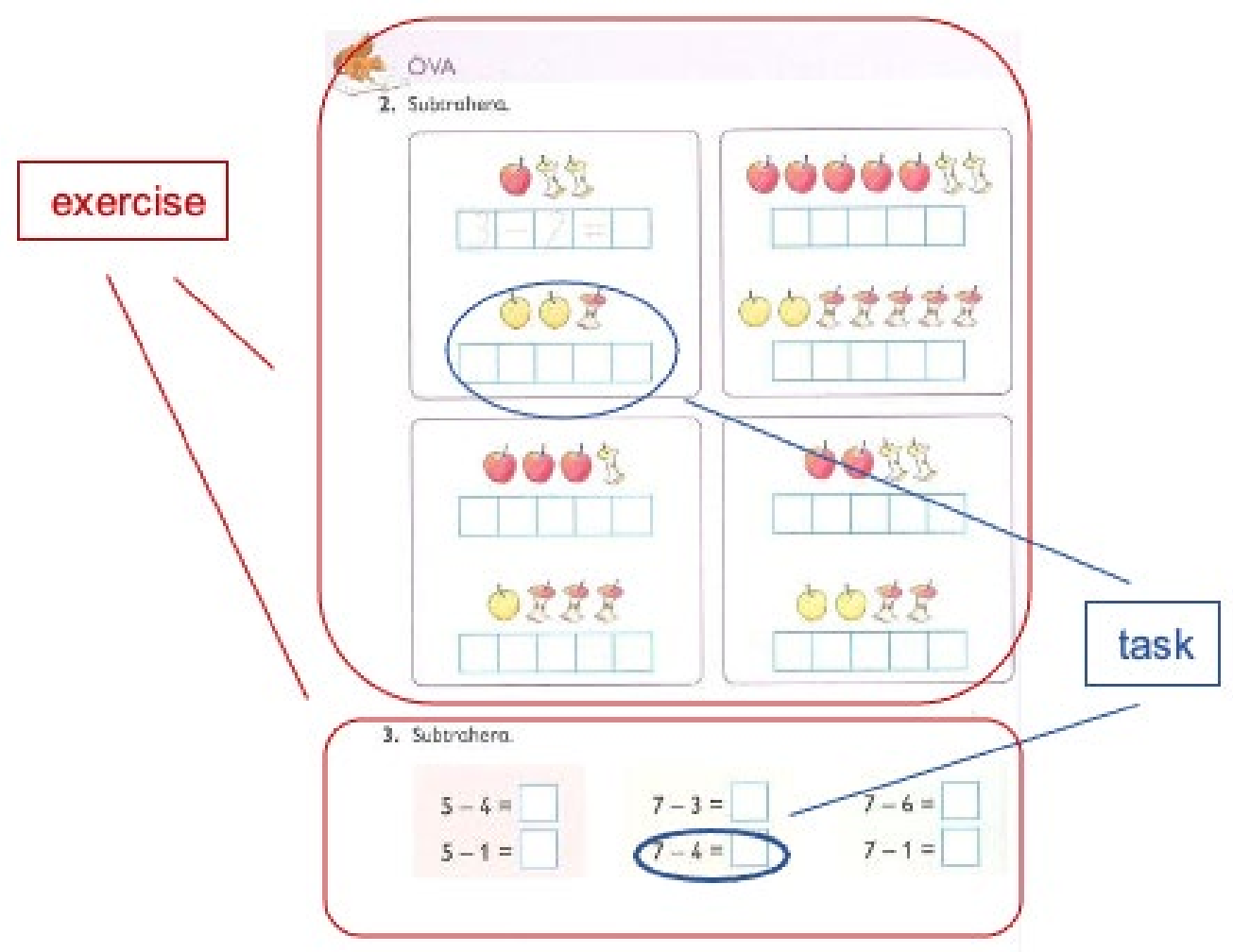

Figure 1. Exercise and task. Ristola, Tapaninaho, and Tirronen (2012). Favoritmatematik 1A. p. 96. Illustrator: Rajamäki, M. ${ }^{1}$

${ }^{1}$ All textbook pages are shown with the publisher's permission. 


\subsection{Framework for analysis}

An analysis in three steps was conducted to understand the students' meaningmaking. First, a textbook analysis of the seven exercises was made to capture the use of images and the affordances designed by textbook authors-that is, the intended affordances to discover a specific mathematical content. Then, the video material and the students' representations (on the copied textbook exercises) were analysed. Lastly, the designed affordance and the students' meaning-making were compared. The analysis evaluated each student's meaning-making when working with textbook images and subtraction as mathematical content.

\subsubsection{Textbook analysis}

In the first step, the textbook exercises were analysed to answer the following question: "Which images exist?", "How are the images used in the exercises?", and "Which affordances are designed into the exercises?". The last question refers to the affordances the students should discover to solve the exercises, the designed affordances. To answer how subtraction is addressed, the mathematical content of the exercises and the mode or modes that carry information for solving the exercise were studied. The teacher's guide was studied to obtain these answers. Here, how subtraction could be addressed in the textbooks will be clarified. Subtraction as an arithmetic operation can be addressed in a specific subtraction situation or not. Fuson's (1992) categorisation of subtraction was used to distinguish subtraction situations: categories included subtraction as change/take from (take away) and subtraction as comparison. Examples of this are shown in Exercise 1 (Figure 2); for instance, exercise $1 \mathrm{~A}$ shows a change/take from situation, where the apples have been eaten. Exercise $1 \mathrm{~B}$ involves subtraction without a specific subtraction situation; the information does not contain a specific situation but rather refers to subtraction in general. It is important to note that there are no exercises showing subtraction as comparison in these textbooks, and therefore no such examples are reported in this article.

\subsubsection{Analysis of video transcripts and representations}

In the second step, the video transcripts were first transcribed based on different modes and using three headings: speech, image, and body language. In the image column, the students' use of images, and cases in which they drew an image to support their calculations, were documented. The students' own representations were placed 
in front of me and supported the analysis. In the third step, I focused on whether the student solved the exercises according to the designed affordance, in terms of subtraction content. Also, how students expressed their approaches to the mathematics textbook images was documented. Finally, the transcripts were coded by reading through the material several times and highlighting using a colour code. The research questions guided the coding of the data. Then condensed meanings were summarised in a matrix, from which four main categories emerged.

\section{Results}

The aim was to understand Swedish Year One students' meaning-making while working with mathematics textbooks focused on subtraction and images. First, a short description of the images in the chosen textbook exercises will be given, then the results will be reported of the students' meaning-making when working with those exercises.

\section{1 The textbooks' use of images and the images' designed affordances}

The studied images are used in various ways, as (a) an event, (b) a resource for calculation, or (c) a guide box. There are also images showing context, images that are not connected to the calculation, and image-like elements in the exercises. These are described in this section (see also Table 1 below).

Some images show (a) an event (Exercises 1 and 2). In these images, something has already happened: The apples have been eaten, or the dots have been crossed out. The student needs to visualise the situation prior to the image to perceive the images according to their designed affordances; for instance, in the first task, in exercise 1, "First there were three apples, and then someone ate two of them. Now there is one apple left." Or, in exercise 2, "The crossed-out dots means that they are no longer there". 

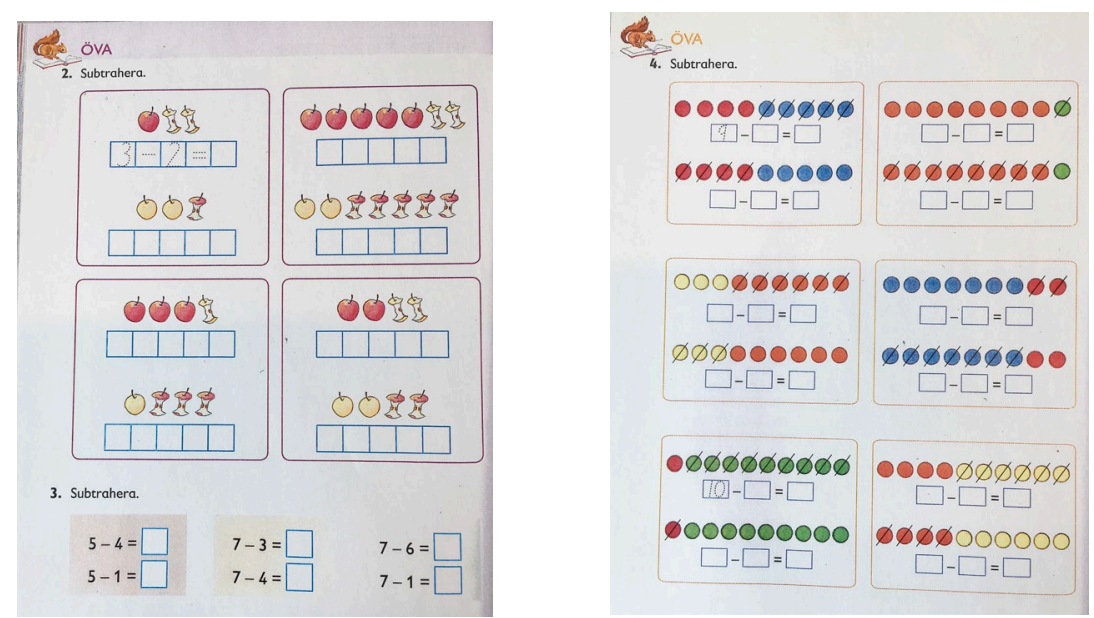

Figure 2. Exercise 1A and 1B. Ristola, Tapaninaho \& Tirronen (2012). Favoritmatematik 1A. p. 96. Illustrator: Rajamäki, M. ${ }^{2}$

Figure 3. Exercise 2. Haapaniemi, Mörsky, Tikkanen, Vehmas \& Voima (2013). Favoritmatematik 1A. p. 140. Illustrator: Rajamäki, M.

Other images could be used as (b) resources for calculation (Exercises 3-7). These images can be used as support for solving tasks, but in contrast to the previous image type, these images are static, and nothing has happened. The images can serve as counters, for instance, the gingerbread cookies in exercise $3 \mathrm{~A}$, the various animals in exercise 4 , or the pencils in exercise 5 , below.
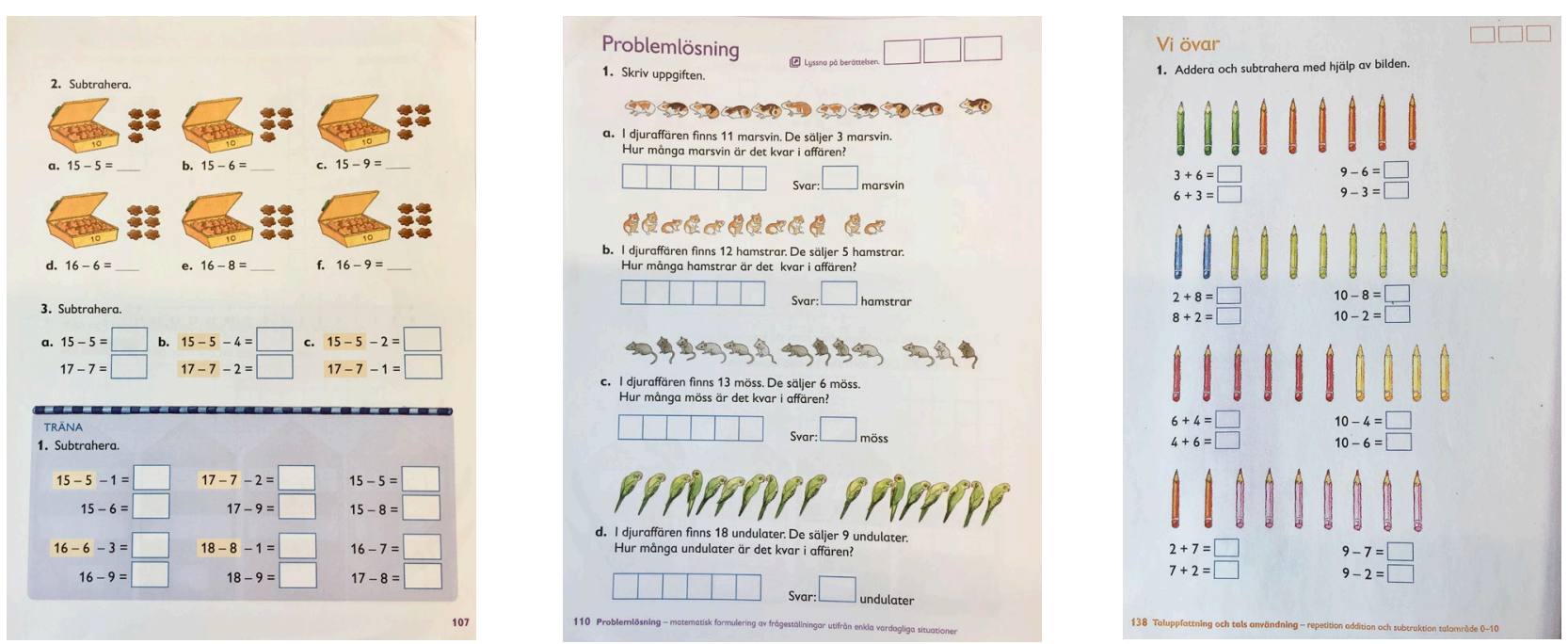

Figure 4. Exercise 3A, 3B and 3C. Ristola, Tapaninaho \& Tirronen (2012). Favoritmatematik 1B. p. 107. Illustrator: Rajamäki, M.

Figure 5. Exercise 4. Ristola, Tapaninaho \& Tirronen (2012). Favoritmatematik 1B. p. 110. Illustrator: Rajamäki, M.

Figure 6. Exercise 5. Haapaniemi, Mörsky, Tikkanen, Vehmas \& Voima (2013). Favoritmatematik 1A. p. 138. Illustrator: Rajamäki, M.

${ }^{2}$ All textbook pages are shown with the publisher's permission. 
Two of the exercises also contain images in (c) guide boxes (Exercises 6 and 7 ) with information about how to solve the exercise. Here, the images provide tasksolving support. They explain how to understand the content that follows. Exercises 6 and 7 also include contextual images that show the counters in a real-world situation.
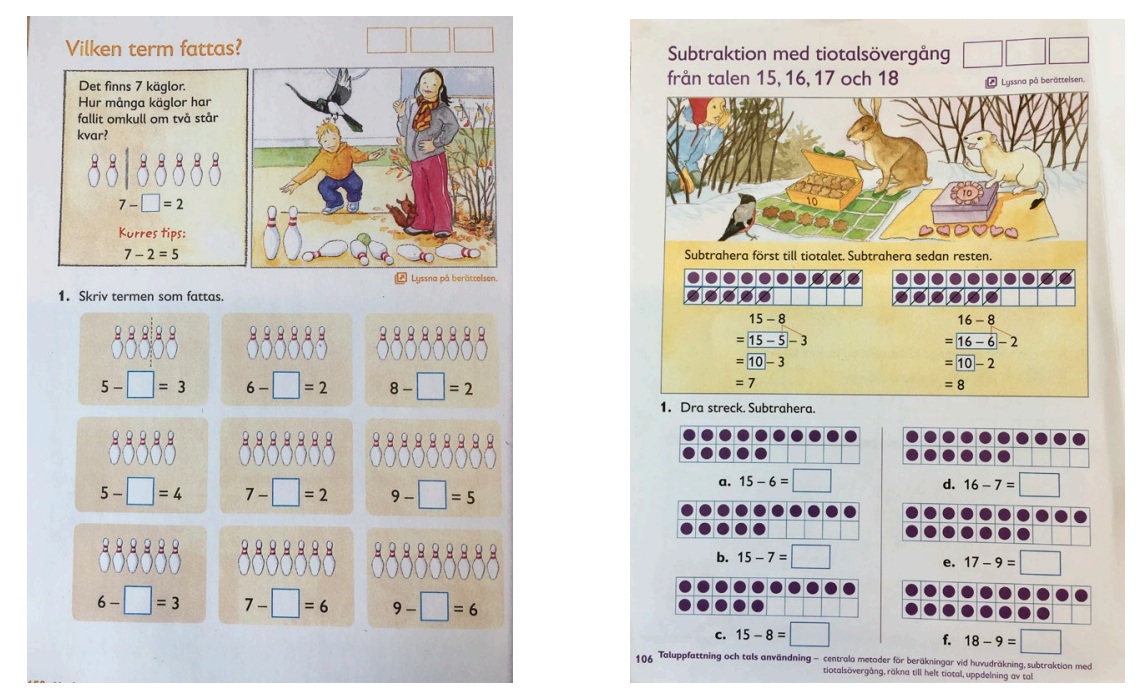

Figure 7. Exercise 6. Ristola, Tapaninaho \& Tirronen (2012). Favoritmatematik 1A. p. 150. Illustrator: Rajamäki, M. Figure 8. Exercise 7. Ristola, Tapaninah \& Tirronen (2012). Favoritmatematik 1B. p. 106. Illustrator: Rajamäki, M.

Sometimes, the exercises contain images not connected to the calculation. This is shown in exercises 1 and 2 by the squirrel in the upper left corner, and in exercise 4 by the striped stick. There are also image-like elements, such as coloured or striped squares around tasks or lines. These sometimes point out one task (Exercise 6), two tasks that are connected (Exercises 1 and 2), an exercise (Exercise $3 \mathrm{C}$ ), a guide box (Exercise 6 and 7), or indicate different columns (Exercise 7). Furthermore, exercise 1's heading includes a coloured square, and all exercises include squares for writing numbers and other mathematical symbols. Colour is sometimes used in the images to demonstrate the numbers in the tasks (Exercises 2 and 5). The table below summarises the image data. 
Table 1. The textbooks' images and the images' designed affordances

\begin{tabular}{|c|c|c|c|c|}
\hline Exercise & Textbook, page & $\begin{array}{l}\text { The images' designed } \\
\text { affordances }\end{array}$ & $\begin{array}{l}\text { Image-like elements } \\
\text { connected to the } \\
\text { solving of the tasks }\end{array}$ & $\begin{array}{l}\text { Other images } \\
\text { not } \\
\text { connected to } \\
\text { the } \\
\text { calculation }\end{array}$ \\
\hline $1 \mathrm{~A}$ & Favoritmatematik 1A, 96 & $\begin{array}{l}\text { Subtraction event as } \\
\text { change/take from }\end{array}$ & $\begin{array}{l}\text { Striped squares around } \\
\text { tasks }\end{array}$ & $\begin{array}{l}\text { Square in the } \\
\text { heading } \\
\text { Squirrel }\end{array}$ \\
\hline 1B & & $\begin{array}{l}\text { No image or subtraction } \\
\text { situation }\end{array}$ & $\begin{array}{l}\text { Coloured squares around } \\
\text { tasks }\end{array}$ & No \\
\hline 2 & $\begin{array}{l}\text { Mera favorit-matematik } 1 \mathrm{~A}, \\
140\end{array}$ & $\begin{array}{l}\text { Subtraction event as change } \\
\text { take from }\end{array}$ & $\begin{array}{l}\text { Striped squares around } \\
\text { tasks }\end{array}$ & Squirrel \\
\hline $3 A$ & Favoritmatematik 1B, 107 & $\begin{array}{l}\text { Resource for subtraction } \\
\text { calculation as change/take } \\
\text { from }\end{array}$ & No & No \\
\hline $3 B$ & & $\begin{array}{l}\text { No image or subtraction } \\
\text { situation }\end{array}$ & $\begin{array}{l}\text { Coloured squares around } \\
\text { part of tasks }\end{array}$ & No \\
\hline $3 C$ & & $\begin{array}{l}\text { No image or subtraction } \\
\text { situation }\end{array}$ & $\begin{array}{l}\text { Coloured squares around } \\
\text { part of tasks and tasks }\end{array}$ & Striped stick \\
\hline 4 & Favoritmatematik 1B, 110 & $\begin{array}{l}\text { Resource for subtraction } \\
\text { calculation as change/take } \\
\text { from }\end{array}$ & No & No \\
\hline 5 & $\begin{array}{l}\text { Mera favorit-matematik } 1 \mathrm{~A}, \\
138\end{array}$ & $\begin{array}{l}\text { Resource for subtraction } \\
\text { calculation as change/take } \\
\text { from }\end{array}$ & No & No \\
\hline 6 & Favoritmatematik 1A, 150 & $\begin{array}{l}\text { Resource for subtraction } \\
\text { calculation and guide box as } \\
\text { change/take from }\end{array}$ & $\begin{array}{l}\text { Coloured squares around } \\
\text { task and guide box }\end{array}$ & No \\
\hline 7 & Favoritmatematik 1B, 106 & $\begin{array}{l}\text { Resource for subtraction } \\
\text { calculation and guide box as } \\
\text { change/take from }\end{array}$ & Square around guide box & No \\
\hline
\end{tabular}

\subsection{The students' meaning-making}

Here, the students' meaning-making when working with the images will be considered. Analysis produced four categories: (1) The student discovers the designed affordance but does not use the image, (2) the student discovers the designed affordance and uses the image, (3) the student discovers the designed affordance and uses the image after support from the researcher, and (4) the student does not discover the exercise's designed affordance. These four categories, and any associated 
subcategories, are described in the following.

\title{
5.2.1 The student discovers the designed affordance but does not use the image
}

In this category, the student does not use the images but instead uses mathematical symbols. This is shown below in relation to exercise 6, where the designed affordance is to practice subtraction as change/take from, which is shown in the guide box, and where the images can be used as resources for calculation.

\begin{abstract}
The student begins by reading the guide box and then writes a mathematical symbol in each empty box but makes no use of the images. I ask him if it is possible to use the image when doing the calculations. He answers: "Yes, you can use the image. Then you draw a line here, between these two" (draws a line in the right place between two bowling pins).
\end{abstract}

This is understood as the student already knowing the content to be taught, and therefore not needing to use the image as support for his calculation. From the information in the guide box, the student understood that the exercise focused on subtraction as change/take from and described to me how the image could support the calculations.

\subsubsection{The student discovers the designed affordance and uses the image}

Another way to make meaning when working with the exercises is to use the image for the calculation. This is done in two different ways, shown in (a) and (b) below. First, for example, in exercise 7 , where the designed affordance is to practice subtraction as change/take from guided by the guide box and using the images as resources for calculation.

The student reads the guide box. Then she looks at the first task and the number to be subtracted " $15-6=$ ". She crosses out the correct number of dots, 6 , counts the remainder, and writes the number " 9 " in the empty box.

So, (a) the images are used as a resource for calculation; the images support the calculation shown in mathematical symbols. The other way is shown in exercise 2, where the designed affordance is to understand the image as depicting an event of subtraction as change/take from.

The student looks at the first task. She counts the crossed-out dots and writes " 5 " in the first empty box. Then she counts the remaining dots and writes " 4 " in the empty box after the equal sign. 
In this exercise (b), the images show an event, they are designed to show a calculation that has already been made, shown in images. This differs from the example above, where the images can be used to do the calculation, but the calculation itself is demonstrated in mathematical symbols. So, the students need to be aware that images are used for different purposes.

\subsubsection{The student discovers the designed affordance and uses the image after support from the researcher}

In this category, the student does not discover the designed affordance by herself, but does so with support from the researcher. The support consisted of posing questions to the student to help the student realise that the images held information that could be used when solving the exercise. An example of this was when a student worked on exercise 4, where the designed affordance was to use the images as resources for calculating subtraction as change/take from.

First, the student reads the text of task 1a aloud: "In the pet shop, there are 11 guinea pigs. They sell 3 guinea pigs. How many guinea pigs are left in the shop?." Then she solves the exercise using mental arithmetic, which is a bit challenging for her. She struggles but continues her work. When the first task is solved, she continues with the same approach while working with the second task. After solving that task, I ask her, "Why are there images here, do you think?" She answered, "Oh, why didn't I think of that! Ah, you can use them as a number line, here [points to the row of hamsters in task $1 \mathrm{~b}] 1$ to 12 , because there are 12 hamsters."

So, with the help of the researcher's question, the student discovered the designed affordance, which she did not by herself. Without my question, the student did not find the images as supportive for the calculation. When she continued working on the next task in this exercise, she used the image to support her calculation.

\subsubsection{The student does not discover the image's designed affordance}

In the categories above, the students, in different ways and to different extents, discover the designed affordances. In this last category, the student does not discover the exercise's designed affordance on her own even after receiving support in the form of questions from me. This means that the student instead discovers other ways to solve the exercises. This is done in three different ways, shown below.

The first way of not discovering the designed affordance is when (a) the student discovers an affordance in the image other than the intended one. This is exemplified by a student working with exercise 1 , where the designed affordance is to use the 
image as depicting an event of subtraction as change/take from. The student does not discover that the apples have been eaten and that she should count the remaining apples. Rather:

The student looks at the task including an image showing five red apples and two yellow apple cores. She counts the red apples and writes the number " 5 " in the first box below the row of apples. Then, she writes "-" in the next empty box. After this, she counts the cores and writes " 2 " in the third box and an equal sign after that. Then she writes the answer " 3 " in the last empty box.

This means that the student interprets the apples as the minuend and the cores as the subtrahend. When she works with tasks that with this method get a negative number, she inverts the two numbers in the calculation (for instance, $1-3$ is changed to $3-1$ ); and says that "It sometimes could be like that".

The second way of not discovering the designed affordance is when (b) the student discovers no support in the image but searches for it. In those cases, the student understands that the image is supposed to support the calculation but does not know how. This is exemplified by the student below, working with exercise 5 . The designed affordance is to use the images as resources for calculation of subtraction as change/take from:

\footnotetext{
The student starts working on the tasks by counting the pencils in the image a few times. She frowns and looks up. After that, she puts her fingers up and uses them to solve the tasks. For instance, she puts nine fingers up when solving the calculation "9 $-6=\ldots$ ". Then she puts six down, counts the remaining, and writes " 3 " on the empty line. Afterwards, I asked her, "Is it possible to use the pencils instead of the fingers for counting?" The student answered: "Yes, although I found no way."
}

This exemplifies that the student knows that the image should be supportive for the calculation, but the image's designed affordance does not prompt this for the student. She solves the tasks with support other than from the images.

The third way of not discovering the designed affordance is when (c) The student discovers no support in the image but creates her own image and uses that image to solve the exercise. For example, in exercise 3A, where the designed affordance is to use the image as a resource for calculation of subtraction as change/take from, the student solves the tasks in another way:

The student first looks at the images in exercise 3A. After a while, he says: "This is a bit hard." I asked him: "Are you trying to use the image for counting now?" "Yes," he answered. Then he draws rows of lines in the margin of the paper and uses them for calculation. He begins with the first task, " $15-5=$ ", counts lines up to fifteen and then faintly crosses out five lines, counts the remainder, and writes " 10 " as his answer. 
So, this subcategory has similarities with subcategory (b) in that the student creates his own support. Of note is that the students who drew their own images did so in the margin of the paper and/or erased the image after using it. This is interpreted as drawing your own images is not a desirable way of solving the tasks.

\subsection{Students' expressions about using images}

Several students spoke about using the images to solve the exercises. Some students also expressed that those who use the images find mathematics hard, and that solving the exercises without using the images is the desirable way of solving them. For example:

In response to my question, "Can you use the image to do the calculation?" one of the students answered, "Yes, but you don't need that if you are good at math."

This approach was also shown in action, when some students used the image to solve the exercise. When they worked with the exercise, I saw that they used the images, but when I asked how they proceeded with the exercise, they did not mention the image. Only when they were specifically asked if they used the image, did students say so. For instance:

Researcher: How did you know how to do this exercise?

Student: I read here (she points to the written instruction) and then I counted.

Researcher: How did you do when you counted? Do you remember?

Student: I counted in my head.

Researcher: Mm. It looked as if you also used the images. Did you?

Student: Yes, I did.

The same approach was seen with finger-counting by some of the students. They did not mention that they used finger-counting when I asked them how they worked. When I asked them about how they used their fingers, they explained that they used them for calculation and described how. Based on the above, using images when working with mathematics textbooks can be understood as non-desirable. An interpretation based on this is that the desirable way of solving the tasks is by using mathematical symbols. 


\subsection{Summary}

In sum, the results show that the students sometimes discovered the designed affordance and sometimes did not. Some students discovered the designed affordance by themselves or with help from me. Some students used the images for calculation, whereas others used mathematical symbols instead. Some students did not discover the designed affordance, despite searching, and some drew their own images instead of using the image in the task. Lastly, some students expressed that using images is for those who find mathematics hard, and that solving the exercises without using the images is the desirable way.

\section{Discussion and conclusions}

The aim of the study was to understand students' meaning-making within the context of Swedish Year One mathematics textbook images, when practicing subtraction. The research questions were designed to determine how the students' meaning-making related to images and the textbooks' designed affordances, focusing on the image mode. The discussion will focus on the students' work with the mathematics textbooks' images, including the work of students who did not discover the designed affordance, and those who discovered the designed affordance but did not use the images. Also, the students' expressed verbally and practically that using images to solve the exercises is for those who find mathematics hard. This will be especially highlighted. This section will encompass a discussion about how the textbook can be part of shaping students' perceptions of themselves as mathematical individuals, or fail to do so.

Students who did not discover the image's designed affordance were conscious that the image was supposed to give support, but could not discover how. This could be compared to the finding of Jellis (2008), that students used the image to solve the task, whether it should be used or not. This allows the conclusion that the designed affordance is not communicated well enough, and the student is unable to make meaning towards the designed affordance. When the images do not communicate the designed affordance well enough, the students need support from elsewhere, typically from a teacher (or a researcher, as in here reported). This relates to Levie and Dickie's (1973) findings from almost 50 years ago, namely that students must learn how to read images. Thus, teachers need to ensure that students understand the design of the exercise when students work individually with the textbook. 
The result also showed that some students chose to use mathematical symbols instead of images, when possible. This is interpreted as the students not needing the images' support; the student knows the mathematical content well enough. But this is argued to have consequences regarding how mathematics is viewed by students and, by extension, how a mathematical individual is viewed. This view of mathematics is also connected to the students' opinions about mathematical images, namely that they are for those who find mathematics difficult, which will be discussed below. Some students expressed that the desirable way of solving the exercises is to do so without using the images, because this signals good knowledge of mathematics. Teledahl (2017) found that most of the students drew images when problem-solving, and that this often supported their problem-solving. Thus, representing mathematics with images may be essential to many students, and should therefore be encouraged when working with the textbook. However, in doing so, the idea of mathematical symbols as the "desirable" mode needs to be challenged. Using mathematical symbols rather than images may obscure the exercise's mathematical content from the students, as this content is often described in the images. For instance, it is possible to describe a comparison using images, but not with mathematical symbols. Using mathematical symbols alone risks teaching students only subtraction, without including different kinds of subtraction situations, which could result in a merely basic understanding of the content. The students must discover the different kinds of subtraction situations, which are sometimes hard for students to recognise, especially the comparison situation (Kinda, 2010). Thus, teachers have significant responsibility to offer different ways of representing mathematics, as do the authors and illustrators responsible for textbook design.

Mathematics textbooks mostly require answers in the form mathematical symbols, which implies that this mode has a particular status. Mathematical symbols' special status can be related to Teledahl's (2017) study, where almost a third of the students used images in their answers. As an interpretation of the findings of Teledahl (2017) as well as the present study, some students would likely choose to answer textbook exercises using images whenever possible. Suppose that students feel the expectation to use mathematical symbols, but would nevertheless benefit more from using other modes (e.g., images). In that case, students may perceive other modes as a sign of failure. This may, in the long run, affect their perceptions of themselves as mathematical. Another example of using images is when students drew their own images. They did so in the margins and sometimes erased them. I interpreted this as 
showing that students' own images are not considered as showing their mathematical skills, and that mathematical symbols are the most desirable way to demonstrate the solutions. The students express, already by age 7-8, that mathematical symbols matter most. This can pose a risk. All students can discover themselves as mathematical and represent mathematics in different ways. But what happens to those who do this through modes other than mathematical symbols? Unfortunately, these students may decide to give up on mathematics; they may feel that the subject of mathematics is not for them, which would be devastating both for the individual and society at large. In conclusion, striving to use mathematical symbols rather than images may prevent students from discovering themselves as mathematical individuals.

In summary, images are always coded and can only be perceived by those who already know the code (Kress \& van Leeuwen, 2006). Therefore, and in light of the results of the present study, images in mathematics textbooks should receive greater attention from teachers, textbook authors, textbook illustrators, and publishers. Textbook images are complex to perceive, and this complexity needs to be highlighted. Furthermore, the present study showed that, whenever possible, students chose to use mathematical symbols when solving the exercises, instead of images. As articulated by students, the hierarchy between images and mathematical symbols could imply that some students may miss out on learning situations if mathematics is taught in modes that they are not confident in. Therefore, this article makes an important contribution by highlighting the role of the image mode in mathematics textbooks and broadening current perspectives on the use of images in mathematics textbooks for young students.

\section{Pedagogical implications}

Concerning the claim that textbook images should receive greater attention in mathematics teaching, teachers are advised to teach students how to use the images (and other communication resources) in mathematics textbooks. Because images can be complex, students will need guidance. In other words, students should only work individually with mathematics textbook images once they know how the images should be used to discover the designed affordance.

The teacher plays a crucial role in guiding students' meaning-making with mathematics textbook images, as do textbook authors, illustrators, and publishers. When writing and developing textbooks, authors and illustrators need to be more 
aware of the difficulties that students experience in order to increase the supporting role of images and thus facilitate students' learning.

Also, textbooks do not invite students to draw their own images (Norberg, 2021). Rather, they prompt the student to respond with mathematical symbols. A mathematics textbook could encourage students to use multimodal representations by leaving space for them to draw an image as support, or by presenting images and mathematical symbols as equally valid ways to answer a given task. This will encourage students to perceive themselves as competent in mathematics.

Mathematics is considered a multimodal subject (O'Halloran, 2005); furthermore, students age 7-8 are at the beginning of their mathematics education. Therefore, they have the right to express mathematics in modes they feel confident using. Mathematics education strives to teach students to use mathematical symbols. Nevertheless, the youngest students should be allowed to use all modes and consider all modes of equal value in meeting students' needs.

The reported study also has a further implication, in that it challenges the distinct status given to mathematical symbols. One solution is to advocate a mathematics education that more often allows multimodal representations. This could, for example, be done by including exercises in which different modes can be used to answer tasks, or exercises that request the student to answer using various modes. These will help students discover themselves as mathematical individuals.

\section{Competing Interests}

The author has no competing interests to declare.

\section{References}

Arcavi, A. (2003). The role of visual representations in the learning of mathematics. Educational Studies in Mathematics, 52(3), 215-241. DOI: https://doi.org/10.1023/a:1024312321077

Arcavi, A. (2005). Developing and Using Symbol Sense in Mathematics. For the Learning of Mathematics, 25(2), 42-47.

Bezemer, J. \& Kress, G. R. (2010). Changing text: A social semiotic analysis of textbooks. Designs for Learning, 3(1-2), 10-29. DOI: https://doi.org/10.16993/dfl.26

Boesen, J., Helenius, O., Bergqvist, E., Bergqvist, T., Lithner, J., Palm T \& Palmberg, B. (2014). Developing mathematical competence: from the intended to the enacted curriculum. The Journal of Mathematical Behavior, 33, 72-87. DOI:

https://doi.org/10.1016/j.jmathb.2013.10.001

Byrne, A. \& Mason, G. E. (1976). When Pictures and Words Conflict. The Elementary School Journal, 76(5), 310-314.

Campbell, P. F. (1978). Textbook Pictures and First-Grade Students' Perception of Mathematical Relationships. Journal for Research in Mathematics Education, 9(5), 368-374. 
Campbell, P. F. (1979). Artistic Motion Cues, Number of Pictures, and First-Grade Students' Interpretation of Mathematics Textbook Pictures. Journal for Research in Mathematics Education, 10(2), 148-153.

Campbell, P. F. (1981). What do students see in mathematics textbook pictures? Arithmetic Teacher, 59(2), 12-16.

Cooper, J. L. \& Alibali, M. W. (2012). Visual representations in mathematics problem-solving: Effects of diagrams and illustrations. In L. R., Zoest \& J. L., Kratky. (Eds.). Proceedings of the 34th annual meeting of the North American Chapter of the International Group for the Psychology of Mathematics Education. (281-288). Kalamazoo, MI: Western Michigan University.

Danielsson, K. \& Selander, S. (2016). Reading multimodal texts for learning - A model for cultivating multimodal literacy. Multimodal Literacy. Designs for Learning, 8(1), 25-36.

Emerson, W. R. \& Anderson, D. (2018). What Mathematical Images Are in a Typical Mathematics Textbook? Implications for Students with Visual Impairments. Journal of Visual Impairment \& Blindness, 112(1), 20-32.

de Freitas, E. \& Sinclair, N. (2012). Diagram, gesture, agency: theorizing embodiment in the mathematics classroom. Educational Studies in Mathematics, 8o(133), 133-152. DOI: https://doi.org/10.1007/s10649-011-9364-8

Dewolf, T., Van Dooren, W., Ev Cimen, E., \& Verschaffel, L. (2013). The Impact of Illustrations and Warnings on Solving Mathematical Word Problems Realistically. The Journal of Experimental Education, 82(1), 103-120. DOI:

https://doi.org/10.1080/00220973.2012.745468

Freeman, B., Higgins, K. N. \& Horney, M. (2016). How Students Communicate Mathematical Ideas: An Examination of Multimodal Writing Using Digital Technologies. Contemporary Educational Technology, 7(4), 281-313.

Fuson, K. C. (1992). Research on whole number addition and subtraction. In D. A. Grouws (Ed.), Handbook of research on mathematics teaching and learning. (243-275). New York: Macmillan.

Gibson, J. J. (1986). The ecological approach to visual perception. Hillsdale, N.J.: Lawrence Erlbaum Associates.

Jellis, R. M. (2008). Primary Students' Interpretation And Use Of Illustrations In School Mathematics Textbooks and Non Routine Problems: A School Based Investigation. Doctoral thesis, Durham University.

Jewitt, C. (Ed.). (2014). The Routledge handbook of multimodal analysis. (2. Ed.). Abingdon, Australien: Routledge.

Jewitt, C. (2016). What next for multimodality? In C. Jewitt (Ed.), The Routledge handbook of multimodal analysis (2. Ed., 450-455). Abingdon, Australia: Routledge.

Jewitt, C., Bezemer, J. J. \& O’Halloran, K. L. (2016). Introducing multimodality. London: Routledge.

Jones, S. R. (2018). Prototype images in mathematics education: the case of the graphical representation of the definite integral. Educational Studies in Mathematics, 97, 215-234. doi: https://doi.org/10.1007/s10649-017-9794-z

Jr Hung-Lin, J. \& Lin, S. (2014). Cognitive load for configuration comprehension in computersupported geometry problem solving: An eye movement perspective. International Journal of Science and Mathematics Education, 12(3), 605-27.

Kempe, A. \& Selander, S. (Eds.) (2008). Design för lärande. [Design for Learning]. Stockholm: Norstedts akademiska förlag. 
Kinda, S. (2010). Assessment of subtraction scene understanding using a story-generation task, Educational Psychology, 30(4), 449-464. DOI:

https://doi.org/10.1080/01443411003689942

Kress, G. R. (2010). Multimodality: A social semiotic approach to contemporary communication. London: Routledge.

Kress, G. R. (2014). What is mode? In C. Jewitt (Ed.), The Routledge handbook of multimodal analysis (2. Ed., 60-75). Abingdon: Routledge.

Kress, G. R. \& van Leeuwen, T. (2001). Multimodal discourse: The modes and media of contemporary communication. London: Arnold.

Kress, G. \& van Leeuwen, T. (2006). Reading images: The grammar of visual design. (2. Ed.) London: Routledge.

Levie, H. W. \& Dickie, K. E. (1973). The analysis and application of media. In R. M. W. Travers (Ed.), Second handbook of research on teaching. Chicago: Rand McNally, (858-882).

Moser, F., Hannover, B. (2014). How gender fair are German schoolbooks in the twenty-first century? An analysis of language and illustrations in schoolbooks for mathematics and German. European Journal of Psychology of Education, 29, 387-407. doi: https://doi.org/10.1007/s10212-013-0204-3

Moyer-Packenham, P. S., Bullock, E. K., Shumway, J. F., Tucker, S. I., Watts, C. M., Westenskow, A., Stephen Anderson-Pence, K. L., Maahs-Fladung, C., Boyer-Thurgood, J., Gulkilik, H. \& Jordan, K. (2016). The Role of Affordances in Students' Learning Performance and Efficiency When Using Virtual Manipulative Mathematics Touch-screen Apps. Mathematics Education Research Journal, 28(1), 79-105.

Norberg, M. (2019). Potential for Meaning Making in Mathematics Textbooks : A Multimodal Analysis of Subtraction in Swedish Year 1. Designs for Learning, 11(1), s. 52-62. DOI: https://doi.org/10.16993/dfl.123

Norberg, M. (2021). Exercise design in mathematics textbooks: the case of subtraction. Nordic Studies in Mathematics Education, 26(1), 5-30.

O’Halloran, K. L. (2005). Mathematical discourse: Language, symbolism and visual images. London: Continum.

Palmer, A. (2010). Att bli matematisk - matematisk subjektivitet och genus i lärarutbildningen för de yngre åldrarna. Diss. Stockholm: Stockholm University, 2010. Stockholm.

Pansell, A. \& Andrews, P. (2017). The teaching of mathematical problemsolving in Swedish classrooms: A case study of one Year five teacher's practice. Nordic Studies in Mathematics Education, 22(1), 65-84.

Presmeg, N. C. (1986). Visualization and mathematical giftedness. Educational Studies in Mathematics, 17, 297-311. DOI: https://doi.org/10.1007/bfo0305075

Presmeg, N. C. (2006). Research on visualization in learning and teaching mathematics: Emergence from psychology. In Handbook of research on the psychology of mathematics education (pp. 205-235). Brill Sense. DOI: 10.1163/9789087901127_oo9

Presmeg N. (2020) Visualization and Learning in Mathematics Education. In: Lerman S. (Ed.) Encyclopedia of Mathematics Education. Springer, Cham. https://doi.org/10.1007/978-3030-15789-0_161

Ramirez, G., Shaw, S. T., \& Maloney, E. A. (2018). Math anxiety: Past research, promising interventions, and a new interpretation framework. Educational Psychologist, (53)3, 145164. DOI: 10.1080/00461520.2018.1447384

Roy, S., Inglis, M. \& Alcock, L. (2017). Multimedia resources designed to support learning from written proofs: an eye-movement study. Educational Studies in Mathematics, 96, 249-266. DOI: https://doi.org/10.1007/s10649-017-9754-7 
Sedaghatjou, M. (2018). Advanced mathematics communication beyond modality of sight, International Journal of Mathematical Education in Science and Technology, 49(1), 4665. DOI: https://doi.org/10.1080/0020739X.2017.1339132

Segerby, C. \& Chronaki, A. (2018). Primary students' participation in mathematical reasoning: Coordinating reciprocal teaching and systemic functional linguistics to support reasoning in the Swedish context. EDeR - Educational Design Research, 2(1), 1-32. DOI: http://dx.doi.org/10.15460/eder.2.1.1150

Selander, S. (2017). Didaktiken efter Vygotskij: Design för lärande. [The didactics after Vygotskij: Design for learning]. Stockholm: Liber.

Selander, S. \& Kress, G. R. (2010). Design för lärande: Ett multimodalt perspektiv. [Design for learning: A multimodal perspective]. Stockholm: Norstedt.

Teledahl, A. (2017). How young students communicate their mathematical problem solving in writing. International Journal of Mathematical Education in Science and Technology, 48(4), 555-572. DOI: https://doi.org/10.1080/0020739X.2016.1256447

Ulu, M. \& Akar, C. (2016). The effect of visuals on non-routine problem solving success and kinds of errors made when using visuals. Educational Research and Reviews 11(20) 1871-1888. DOI: https://doi.org/10.5897/ERR2016.2980

Usta, N., Yilmaz, M., Kartopu, S., \& Kadan, Ö. F. (2020). Impact of the KWL reading strategy on mathematical problem-solving achievement of primary school 4th graders. The Journal of Educational Research (Washington, D.C.), 113(5), 343-363. DOI: https://doi.org/10.13189/ujer.2018.061014

van Leeuwen, T. (2005). Introducing social semiotics. London: Routledge.

Wilson, A. A. \& Landon-Hays, M. (2016). A Social Semiotic Analysis of Instructional Images across Academic Disciplines. Visual Communication, 15(1), 3-31.

Yackel, E. \& Cobb, P. (1996). Sociomathematical Norms, Argumentation, and Autonomy in Mathematics. Journal for Research in Mathematics Education, 27(4), 458-477. DOI: https://doi.org/10.2307/749877

Österholm, M., Bergqvist, T., Liljekvist, Y. \& van Bommel, J. (2016). Utvärdering av Matematiklyftets resultat. Slutrapport. Umeå: Umeå universitet.

\section{Mathematics textbooks}

Haapaniemi, S., Mörsky, S., Tikkanen, A., Vehmas, P., \& Voima, J. (2013). Mera favoritmatematik. 1A. [More Favourite Mathematics. 1A]. Studentlitteratur.

Ristola, K., Tapaninaho, T. \& Tirronen, L. (2012). Favorit matematik. 1A. [Favourite Mathematics. 1A]. Lund: Studentlitteratur.

Ristola, K., Tapaninaho, T. \& Tirronen, L. (2012). Favorit matematik. 1B. [Favourite Mathematics. 1B]. Lund: Studentlitteratur. 